\title{
UNDERSTANDING THE UNINTENDED CONSEQUENCES OF ONLINE TEACHING
}

\author{
R. J. Rudman \\ School of Accountancy \\ Stellenbosch University \\ Stellenbosch, South Africa \\ https://orcid.org/0000-0002-3789-2386
}

\section{ABSTRACT}

In March 2020, South Africa entered a hard lockdown and students and academics, were forced to transition into the fully (emergency) online remote learning space. Lecturers innovated, adapted and learnt how to use many new tools in a short period of time. Despite the changed context in which lecturers find themselves, the traditional academic and professional expectations on staff remain unchanged. Lecturers had to balance personal and professional decisions as well as disruptive technologies. This, with the added responsibility for the governance of these technologies and the uncertainties they represent. Each lecturer accepted a set of risks associated with online teaching. The purpose of this article is to outline and reflect on the problems and challenges relating to streaming and recording lecturers. Online education works effectively in developed countries. It faces practical issues at a scale that traditional learning does not. Notwithstanding these practical issues, there are additional fundamental downsides teaching online which gather around three themes: changes in teaching practices, changes to the student experience, and the re-shaping of institutional strategy and responsibilities specifically relating to this new digital environment.

Keywords: online teaching, online learning, risks, consequences

\section{INTRODUCTION}

March 2020, the month the world stopped, and it wasn't a movie. 15 March 20:00, South Africa heard the greeting "My fellow South Africans" and lockdown was announced. 16 March 12:00, student activities ceased on campus. 30 March 08:00, the material for the first week's online lecture material was ready.

On 26 March 2020, South Africa entered a hard lockdown and students and academics, were forced to transition into the fully (emergency) online remote learning space. This process was a steep learning curve for students and lecturers alike. Everyone knew it wasn't about simply taking the face-to-face experience and replicating it online. For some, the expectation of replicating the face-to-face experience online was however there. There were many tools that lecturers had not used to teach before. In planning how to teach, three key principles were 
considered: (i) how to make students feel like they are not alone, (ii) how to make the transition as easy as possible for students and (iii) how to assist students through effective online learning activities that would engage them in their own learning process and make a success of the academic year. These principles were almost exclusively student-focused. Lecturers innovated, adapted, and in the process, they tacitly agreed to waive various of rights to ensure the transition to online learning was successful, because there was insufficient time to consider the unintended consequences.

Despite the changed context in which lecturers must now work, the traditional academic and professional expectations on staff remain unchanged, staff have to navigate this new world of life, and work. They must balance personal and professional decisions as well as disruptive technologies. This, with the added responsibility for the governance of these technologies and the uncertainties they represent. Each lecturer knowingly and, in most cases, unknowingly, accepted a set of risks associated with online teaching. As is the case with all new technology, business had not caught up with all the changes during the initial stages of the COVID-19 pandemic. Universities were no exception.

The purpose of this article is to outline and reflect on the problems and challenges relating to teaching online. Online education works effectively in developed countries such as Norway, Sweden, where stable electricity, device availability and a reliable internet connection are in place. It faces many practical issues, like background sound, and difficulty with focus at a scale that traditional learning does not. Notwithstanding these practical issues, there are some additional fundamental potential downsides of streaming and recording lecturers which gather around three themes: changes in teaching practices, changes to the student experience, and the re-shaping of institutional strategy and responsibilities specifically relating to this new digital environment. These are discussed in the following sections.

\section{BALANCING STAFF PRIORITIES}

Besides finding the balance between student needs and increased student demands, lecturers in academia have always struggled to find the right balance between personal time, teaching obligations and research commitments. Balancing these competing demands has become more difficult in the remote learning environment.

Online teaching is more time consuming than face-to-face teaching, mainly because lecturers were required to learn how to teach online, while teaching at the same time. Course design and grading are also major time-consuming activities which required re-engineering. This reinvention of the core responsibilities in academia required significant initial resources investment in time, which substantially increased teaching workloads. The need to provide a 
student with a world-class standardised online experience required time to develop standards guidelines required and collaboration time to ensure a consistent feel and appearance in the material and online experience. Although this collaboration had benefits, inevitably staff that were more proficient in online course design, were roped into assisting in other courses outside of their normal work allocation.

Typical small tasks become time-consuming. For example. Irrespective of the volume increase in correspondence over multiple platforms, written communication takes more time than verbal correspondence. Something as simple as a class announcement has become more time-consuming. Class announcements, traditionally heard by everyone in class, are replaced by discussion board announcements. These are not frequently read. Instead of searching for the answer, the keyboard warrior influence, became more apparent with every small question being asked via email or on a discussion board. Each piece of correspondence is required to be answered. Students also had the expectation of instantaneous responses to queries, with correspondence no longer being restricted to office hours. Moreover, since students can reply to other students queries on discussion boards and chats, these discussions need to be monitored by teaching staff to ensure the content being posted is factually correct and does not contain biased information. If left unchecked, online platforms could lead to incorrect information spreading, information overload and wasted time as students need to work through all this digital noise. This responsibility shifted to lecturers in the absence of funding for teaching assistants.

Limited time is not the only problem influencing staff priorities. Given the difficulty in authenticating students and authenticating a student's work as his/her own, the integrity of assessments was called into question. The number of disciplinary cases at Universities across South Africa increasing with charges of collusion between students, students writing on behalf of other students, copy and pasting from examples and using content sharing platforms and subscription services to cheat and get assessment answers. In many cases, the academic staff, not the disciplinary divisions, were tasked with collating evidence.

Research pressures did not subside. Devoting more time to teaching and related online activities, impacts on other academic and professional responsibilities, in particularly research commitments. For junior staff, this could negatively impact on their research portfolio and therefore future promotion prospects.

Another challenge arose around student evaluations, with a low response rate and students' confusion of technological issues with lecturers' performance issues, where many would argue technology problems belong to the University. This presented a challenge, as the data collected cannot be used as part of the annual performance reviews. 
Not being able to engage with peers between lectures and sitting at home also increased students sense of isolation, with lecturers reporting a decline in student well-being with lecturers being expected to provide students with emotional support, despite not being trained to do so, nor additional resources being made available. Even with counselling services being available at universities, it is still emotionally exhausting when students insist on telling lecturers about their mental health issues, with the expectation of support.

This imbalance in time-allocation and additional priorities manifests in the psychological impact relating to the move to an online model of delivery resulted in both lecturers increased sense of isolation and anxiety. This also impacted the student learning experience.

\section{STUDENTS LEARNING EXPERIENCE}

Recordings and live-streaming diminish the students learning experience in subtle and explicit ways. Students may miss the nuances of a lecturers' facial expression, gestures, while lecturers may inhibit their action to accommodate a fixed camera, thus morphing into performing with modes of presentation that play up to the camera and are unnatural. Being recorded may also impact how lecturers engage with different learning formats. This applies to live in-venue lectures being recorded or directly streamed lecturers. Lecturers may become cautious about interactive formats for the fear of making mistakes or saying something controversial. Anonymity of the online setting may embolden some students; at the same time, it might intimidate or silence others.

Making recordings available led to decline in attendance of the live lectures and further de-personalising of learning. A live lecture cultivates students' capacity for sustained attention to a narrative unfolding in real time, and thus reinforces positive active learning habits such as effective notetaking. Research shows that taking notes enhances retention of information. Many students, unfortunately, believe that they can just re-watch the recording, if their memories fail them. They also take screenshots of additional notes that the lecturer writes instead of copying it down. Recordings or click-through presentations, on the other hand, reinforce passive learning. Research shows that a human brain cannot distinguish between educational content compared to entertainment content displayed on a screen, thus limiting learning. Further, recordings may also encourage procrastination and then "binge studying" around the time of examinations. Many students are not making responsible decisions. Because recordings are made available, students no longer feel obligated to keep up to date with the work. They believe that they can "catch up" and underestimate the amount of time they would need to watch the recordings before they can start to engage in any independent learning activities. With selfdiscipline lacking, the lack of a forced routine negatively impacts students who cannot self- 
regulate.

Given students preference for passive learning associated with recordings, once streaming and recordings are introduced, there is generally an increase in scrutiny and complaints regarding the differences in teaching styles of lecturers by students. To avoid the complaints, lectures then tend to or are forced to take the path of least resistance, irrespective of the pedagogical motivations.

\section{STRATEGY AND RESPONSIBILITIES RELATING TO THIS NEW DIGITAL ENVIRONMENT}

These pedagogical challenges are not the only concerns academic staff must consider. A digital environment places additional burden on lecturers to take responsibility for managing student online behaviour, particularly since universities have not kept up to date with the changes in the technology landscape, nor have their policies been updated. In a rush to design a workable online learning approach in the face of the uncertainties surrounding the COVID-19 pandemic, the personal and other risks that live-streaming and recordings created have been overlooked by the University or they are planning to only be addressed in the future. In the meantime, however, lecturers are forced to continue to be expose themselves and the University to risks and therefore are presumably responsible for mitigating these risks themselves, until such time as the University has considered, understood, prioritised and addressed the risks of online teaching. The matters to consider include aspects relating to access, loss of academic freedom and ownership rights, as well as a loss of privacy and identity.

\section{Unauthorised access controls}

The pace of adoption of online learning resulted in many lecturers not understanding the appropriate access controls and operating settings around the online platforms used. Incorrectly configured settings may result lecture recordings being shared throughout the entire university with even non-registered students gaining access. Tech-support focused on implementation, not operations, which left organisational controls lacking. Since most lecturers want to reduce the barriers to entry to make it as convenient as possible for student to access learning material, this increased ease of access resulted in unauthorised persons (i.e., hackers) doing unauthorised things with the online material, as well as authorised persons (i.e,, other students and staff) using the material in a unauthorised manner. Lecturers may want to retain some personal intellectual capital to differentiate themselves from their peers, whether it be for a better student evaluation or to simply create a differentiated classroom experience. Lecturers may also want to avoid situation where they put in effort and another lecturer uses their material. The 
temptation to grab last year's recording and simply re-cycle it, is significant, even if it is a recording made by a colleague.

Inappropriate access controls would result in a loss of intellectual property if unauthorised access is gained to a university's intellectual property. Hackers could steal material on a large scale and use it on other platforms, at the same time registered students could also download learning material and upload it to other platforms such as CourseHero for their own commercial benefit. This risk is not limited to course material. Once a recording is made, it lasts indefinitely and is easy to share. There is probably little commercial value in a students' comments today, but that is not to say that it would not have commercial value in the future. Let's assume student generated content included, for example, video- and audio of a then unknown student while enrolled in the School of Arts who becomes a top selling music artist in ten years' time. Those recorded would be worth a fortune. In the same vein, recordings become available for scrutiny years to come. As morals and values change over time, an innocent student comment today that is immortalised in a recording, could become viral in the future and potentially damage a student's reputation as an employed adult. Certain business sectors and the political environment is particularly susceptible to this future reputational risk.

\section{Acceptable behaviour}

Students who are authorised users could also do unauthorised things. Students could post inappropriate content or communicate in a manner which is in breach of the universities code of conduct or communication policy. Students become fairly familiar in discussions and on a discussion form or chat and may forget to keep discussions using a professional tone and manner similar to that of how they would during an in-person face-to-face lecture. Trolling, harassment, doxing or even cyberbullying of fellow students by means of posting potentially harmful or cruel text following a question posted in chats has become a problem. Most frequent example is where words can be taken out of context to become a sound bite or social media post that becomes a meme and goes viral on, for example, StelliesRage.

Inappropriate content is not only limited to discussions. Unauthorised participants could load links, disguised as polls or quizzes, to inappropriate content that could include phishing links. In South-Africa, there has been other examples of innocent instances of students accidentally switching on a camera and being partially dressed or having someone partially dressed walking past the camera, as well as intentional attempts to take control of lectures by unmuting microphones, Zoom-bombing live lecturers and hijacking lectures with students protests.

Inappropriate behaviour also extends to lecturers. Telling a colleague, a story of something 
that happened or "unbelievable" thing a student did or said is not the same as sending them a screenshot or link to it.

Where malicious online activity does take place, it would constitute "misconduct" but the difficulty comes in determining which policy and which applicable section of the policy is breached. Moreover, it is difficult to obtain appropriate digital evidence for disciplinary cases. Digital detective controls, such as logs, frequently are not as well developed as in software packages of other industries.

\section{Malware and other intrusions}

Unauthorised access or behaviour is not only limited to users. It took academics time to realise the risk of predatory publishing. Predatory conferences are on the rise. Both made possible by the internet. In recent years, academia has increasingly become a target for online attacks, with a host of phishing websites for popular platforms like Google Classroom and Zoom having popped up. Suspicious domains being registered for Microsoft Teams and Google Meet. Users who land on these phishing pages are often tricked into clicking URLs that download malicious programs or inputting their login credentials. These later can be used to facilitate social engineered attacks, malware and even distributed denial of service (DDoS) attacks.

\section{Loss of professional academic freedom}

Besides unauthorised access and unacceptable behaviour, authorised users in the online space also give away some freedoms and rights. A lecture venue has historically been considered a safe space where students and staff were afforded the academic freedom to critically discuss contentious or topical real-world issues and real-life incidents as it relates to course material. This is particularly important in an era where many academics profess a commitment to the development of critical thinking skills.

Being recorded or not knowing who is present in an online lecture may inhibit this academic freedom, discouraging lecturers and students of taking controversial views, reduces participation and sharing of own experiences and views (as noted previously). Lecturers might engage in avoidance behaviour and deliberately stifle discussion of contentious topics to protect themselves and their students. This is particularly relevant in the era of populist politics and cancel culture. This is potentially increasing reputational risk that could have far ranging consequences.

- When being recorded, the professional and personal risks unfortunately go beyond the embarrassment of having students seeing a lecturer's messy house, or a dog interrupting 
a lecture, or where a lecturer makes mistakes or makes a potentially disagreeable argument. This includes both statements as part of a lecture, as well as audible student comments in the background clearly not intended to be recorded. It only takes one or two disgruntled keyboard warriors with time on their hands to lodge a complaint or send multiple emails until the complaint is heard.

- Any statement, regardless of how innocent or innocuous, has the potential to be interpreted negatively if taken out of context, and edited for other purposes. An example of two recent incidences involved the much-publicised extracts of recordings from sessions involving Prof Adam Habib and Lwazi Lushaba. Once the social media-mob, traditional media and political parties took the story on, the damage was done.

It might be argued that a full recording might provide full context, but depending on how the recordings are made, or microphone volumes, recordings might only capture one side of the argument. Recording technology has not evolved to the extent that everything that is said is recorded. Highlighting the relevance of the short-coming, lecturers are frequently encouraged to repeat the questions asked by students online and in the venue, to ensure that everyone can hear the question.

\section{Loss of ownership}

In addition to a loss of academic freedom, academics could also lose ownership of identity. Universities have always taken ownership of products produced by academic staff under their employment contracts. It is often assumed that this has only been in reference to written works or artefacts produced which do not involve a lecturer's personal physical being (i.e., voice and image). The reason for this assumption is simply due to the fact that in certain fields historically very little audio and video material had been created. Creative works, video and audio material has been limited to the Arts and some Social sciences. Some universities have separate policies governing written works and artefacts as opposed to voice and video recordings, while others may have purposefully broad catch all policies and include recording as part a university's record of information asset. The question does arise, who owns the material, the voice, images and recordings of a lecturer physical being, as well as how long is an acceptable period of use when a lecturer changes courses or resigns. Or in the case of Dr. Francois-Marc Gagnon, an art history lecturer from Concordia University in Montreal, Canada, whose videos are being used after he passed away. But it is not that simple, the software package being used could also impact the ownership of the recording. If recordings are made through freeware or trial version software, depending on the license arrangements, the software developer could own the output (i.e., recording). Another related risk arises where the lecturers inadvertently include 
copyrighted material as part of lecturers which could expose a lecturer or university to litigation.

This leads to the question of who protects the lecturer and the university. In most cases, it appears that the onus is placed on the lecturer to identify that material is used in an inappropriate manner, to identify the material as belonging to the university and to identify the parties involved in the use of the material. Given the nature of the internet, it is however not always possible to identify who are the parties involved. This anonymity is problematic. Should the parties involved not be identified or the party responsible is no longer affiliated to a university, the university and more so the lecturer, would have great difficulty in successfully removing material from any third-party website without expending significant resources. As much as the university may purport an intention to protect lecturers' personal information, other rights and its intellectual property (as far as the law requires), it is unlikely that a university would be willing to spend significant resources to protect intellectual property which does not generate significant income on its own and is easily replicable. With reference to loss of academic freedom mentioned earlier, it is also unlikely that the university would be willing to incur legal costs in those instances where a malicious edit of a recording cannot be identified as originating from a university and the only consequence of the action is the personal reputational damage to a lecturer and not the university.

\section{Privacy}

Besides academic freedom and loss of ownership, there are also wider ethical issues such as privacy and identity, at play. Recordings could infringe on a person's perception of privacy. Although privacy is a right included in the constitution, legally there isn't clarity on whether a lecturer or student can refuse to be recorded. Non-consensual recording could be viewed as an invasion of privacy. It could be argued that a student can retain his or her privacy and the right to choose if he or she is recorded by giving a student the choice not to attend a session which is recorded (i.e., opt-out) or not participate in the lecture, but the choice is restricted if a course has a minimum attendance or participation requirement. This limitation of choice extends to lecturing staff. Most employment contract and conditions of service do not explicitly state that lecturers may be required to record or live-stream their personal physical being in the performance of their teaching duties. If live-streaming and recording of lectures are forcibly required of lecturers, then the choice is taken away from them. Further implications could be that:

- There is a permanent change in mode of teaching at a university. This may constitute a significant unilateral change to a lecturer's conditions of service which may require a 
proper consultation process to be followed.

- If recordings are to be treated as the universities assets, then there is an obligation that it should be safeguarded as any university record and ensure that it is processed fairly, transparently and lawfully and be securely stored in an authorised recordkeeping system and take changing circumstances into account, since these recordings may contain personal information of students and staff. This personal information can take many forms and could potentially become a data breach. For example, chats and discussion forms are not completely anonymous and log on credentials or comments displayed may contain "personally identifiable information" which might contravene legislation if disclosed. Another student may take a screenshot and share it on social media platforms.

- Depending on the legal jurisdiction, there may be legal requirements when making online recording to ensure a university complies with the appropriate laws relating to privacy regardless of where we are located or how we are connecting. Sessions with international colleagues or students may require additional thought and ensure that none of the information being shared be of a kind that may be subject to defence trade controls. In South-Africa, much attention has been given to the Protection of Personal Information (PoPI) Act, but the European General Data Protection Regulation (GDPR), which regulates how personal data is collected, processed, stored and transferred relating to European states, has created a ripple of changes in data protection and privacy law across the world and may impose additional requirements. For example, GDPR requires informed consent from the participants.

Personal data also include biometric data.

\section{Future use of biometric data}

Using a photo to make a meme of a lecturer, may be embarrassing. Former President Donald Trump popularised fake news. Deepfakes, on the other hand, has changed the playing field. A deepfake is a video of a person in which their face or body has been digitally altered so that they appear to be someone else, typically used maliciously or to spread false information. Deepfakes leverage powerful techniques from machine learning and artificial intelligence to manipulate or generate visual and audio content with a high potential to deceive.

The biometric data contained in video and voice recordings, which become the source of data for a deepfake, could expose lecturers to future security risks. By generating recordings, a lecturer is generating hours of biometric data which can easily be used to make deepfakes or be used in other forms of voice synthesis or cloning. There are several existing examples for the 
use of personal biometric data in digital access controls: facial recognition, voice and fingerprint recognition to, for example, unlock phones, banking apps, etc. In South-Africa, Investec Bank and Discovery Health already use voice recognition to verify identify and authorise financial actions.

What is unclear is to what extent recorded versions of biometric data from lecture recordings could be used by other parties for fraudulent access. Software such as Faceswap or Lyrebird is already in existence which can synthesise or clone voice from a small sample of audio clips. There is already software which can create new animated clips (i.e., realistic moving images) from video screengrabs (one example is MyHeritage Deep Nostalgia). Stealing someone's biometric data is not as farfetched as people might think. There are various documented international cases of voices cloned from online recordings being used to authorise fraudulent transactions, causing financial loss to the person who was recorded. While universities give consideration to the safeguarding of personal information of students and staff stored in traditional databases, little consideration is being given to the safeguarding of biometric data or its potential further legislative implications. Currently, there is no global framework governing the collection or use of biometric data, with the European Union proposing its first legal framework and China having issued a draft standard.

\section{CONCLUSION}

Universities are rich, yet fragile, human ecosystems. New technologies can improve this ecosystem, while at the same time re-configuring it in a disruptive manner. As the full ramifications of technology become clear, universities will need to become more attuned to the changing demands on its most valuable resource, being its people, as well as the complexities of the digital economy. They need to understand and react to the unintended consequences of online teaching, because in a digital world everything becomes permanent in an instant.

\section{ACKNOWLEDGEMENT OF PLAGIARISM}

This article outlines the current and future risks relating to online teaching. The article itself is also an example reflecting the modern reality of online learning where controls are not appropriately designed or implemented and where information and material is freely available and shared conveniently without acknowledging the source. The "like" and "share" generation grew up with a different view of sharing and re-using content. In school, learners are taught not to photocopy books, nowhere are they taught the same rules can apply to videos they "like" and "share" on Facebook, YouTube or Instagram. Like the current generation of students who will share learning material sourced online without acknowledging the source, the content of this article was sourced online without acknowledging the source to highlight the risk. It must therefore be acknowledged that parts this article was plagiarised and unreferenced and I must thank those academics who thought about the personal and professional risks before me and placed their thoughts and ideas online with the potentially misplaced belief that they would be acknowledged. 
This article has no references. It does, however, have a Turnit-in similarity index score of $4 \%$. The Turnit-in report is available on request.

It is hoped that this article encourages debate about the unintended consequences of online learning. 